\title{
Sustaining crafts and livelihoods: handmade in India
}

\author{
By Sharmila Wood
}

Sharmila Wood has worked in the creative and cultural industries in India, the USA, and Australia. She is currently working as a consultant in New Delhi. She recently wrote and edited Co-Creating: Designer meets Artisan for UNESCO and Craft Revival Trust. Prior to her time in India, she managed an Aboriginal Art Centre in Western Australia. Sharmila holds a Master of Art History \& Curatorship with Merit from the University of Sydney. She has been published in The Australian newspaper, and DRONAH, the Context Journal, India.

Abstract: This paper examines the current state of the craft sector in India, exploring how a growing interest from consumers in ethical and sustainable materials, processes and objects, is impacting Indian artisans and craft workers. To illustrate how those in the Indian craft sector are dealing with issues related to sustainability and craft, the paper discusses the work of AVANI in the Himalayas, and Khamir Craft Resource Centre in Bhuj, Gujurat.

\section{Paper}

Over the last century, industrial production has steadily replaced traditional handmade production in countries around the world. In India, this has meant the loss of traditional markets for artisans and craftspeople, who struggle to compete against the economic and production efficiencies of volume manufacturing, ushered in by advanced technology, and mechanization. However, in recent times, new markets have emerged, particularly amongst urban consumers, who have ascribed craft, and the handmade, with ethical, environmental, and socio-cultural value. Indian artisans are well positioned to tap into this emerging market, as consumers develop more of an understanding about the externalized environmental and social costs of a product, as it moves from extraction to production, to distribution, to consumption, and disposal. 


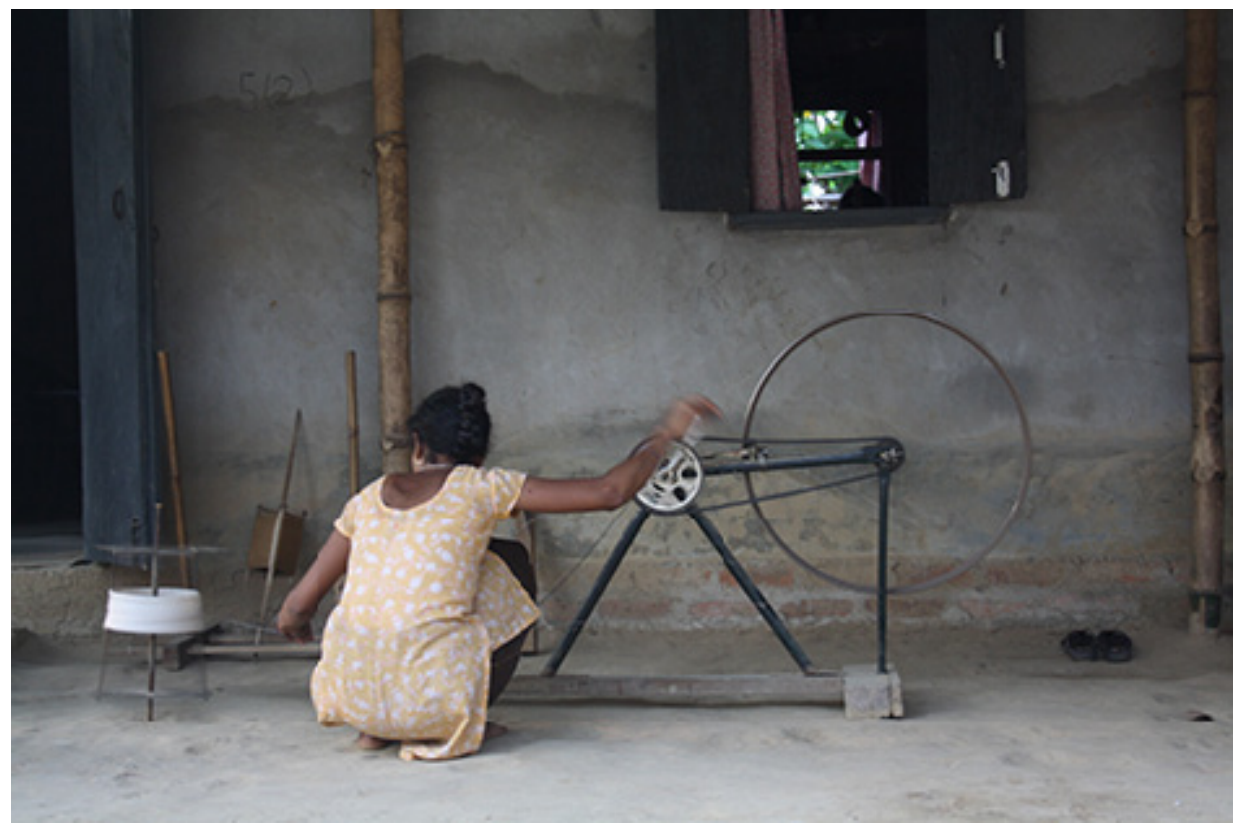

Plate 1: Handloom weaver using bicycle parts to help with spinning silk in her backyard in rural Assam.

Photo: Sharmila Wood.

As the link between consumption, and resource depletion, industrial production and environmental degradation, enter the mainstream discourse, craft provides a framework for explorations of how ethical, sustainable and environmental principles are manifested in, and through, particular materials, processes, and objects. The term, 'conscious consumption' is used to describe this ethically driven consumer movement, where shopping is conducted in a critical or analytical way. ${ }^{1}$ Jatin Bhatt in Philosophy and Practice of Crafts and Design, argues that not only do handcrafted objects form an important part of the creative cultural industries, they also occupy a space to counter technoaesthetic dominance, for crafts inherently represent, to the patron of sustainable practice, a connect and concern with material, and the environment. ${ }^{2}$

The perceived connection between craft and sustainability has provided an opportunity for employment in the crafts sector. As markets open up in urban metros within India, and abroad, craft producers are able to continue selling their products and generating livelihoods. In India, craft is the second largest employer of people living in rural areas after agriculture, and the sector, has employment requirements for millions of people, whose livelihoods and income

1 Dr Alex Nicholls \& Charlotte Opal, Fair Trade: Market-Driven Ethical Consumption, Sage Publications Ltd, 2005.

2 Jatin Bhatt, 2007. Philosophy and Practice of Crafts and Design, Seminar Magazine, [online] Available at: <http://www.india seminar.com/2007/570/570_jatin_bhatt.html>[Accessed 30 April 2010]. 
are dependent on selling their craft. ${ }^{3}$ As Ramba Ben, a mirror work craftswoman from the Madotra Village in Banaskantha stated: 'Our lives hang on the thread I embroider.' Maggie Baxter has worked with artisans in India, and through her work with the craft enterprise NGO, Shrujan, observed the benefits of providing women, in particular, with a regular income from their craft production. In her article, Threads of Life, which observes the work of Shrujan, she writes:

'On a material level, the women have been able to improve the lives of their families. They can invest in land, afford good health care and provide better nutrition by purchasing cows and goats, and they can do this at their own pace, from home and without leaving the village. On a personal level, economic empowerment has transformed these women into confident and competent business women.' ${ }^{\prime 4}$

For women, craft is not only an important source of supplementary income, it also has implications for increased bargaining power, and socio-economic status.

Jaya Jaitly stresses the importance of sales channels for ongoing survival of the sector. She points out that the history of crafts in the past 100 years indicates that wherever industrial goods competed with local ones, the latter died out and craftspeople turned to other occupations. Similarly, as old cultural practices were supplanted by new technologies, the craft person lost their traditional source of income. Jaitly argues:

'The most crucial component to ensure employment, i.e. sustainable livelihoods in craft occupations is the market. Without this there can be no security. If the crafts person is sure of selling his/her goods, the motivation and confidence needed to access raw material, give time to ensure a fine quality finish, seek funds through loans to fulfill orders and finally, to pass on skills to the next generation, comes automatically. ${ }^{5}$

Craft is not only an important source of livelihood; it is often connected to sociocultural traditions, and elemental to the preservation of cultural diversity and identity. Lucy Donkin describes this relationship between craft and the social fabric, in Crafts and Conservation, 'Crafts are not simply a particular way of making objects, but are inextricably bound up with the structures, values, history and identity of the communities in which they are practiced. ${ }^{6}$

Indian handicrafts are, historically, part of a generation to generation learning, passed down along a line of inheritance, and the transfer of tacit knowledge. Craft has multiple meanings, and functions, ranging from personal consumption,

3 Jaya Jaitly, 2007. Employment in the Craft Sector, One India, One People, [online] Available at: <http://www.craftrevival.org/voiceDetails.asp?Code=176> [Accessed 20 April 2010].

4 Maggie Baxter, 2003. Threads of Life, Seminar Magazine, [online] Available at: $h$ ttp://www.indiaseminar.com/2003/523/523 maggie baxter.htm [Accessed 25 April 2010].

5 Jaya Jaitly, 2007. Employment in the Craft Sector, One India, One People, [online] Available at: <http://www.craftrevival.org/voiceDetails.asp?Code=176> [Accessed 20 April 2010].

6 Lucy Donkin, 2001. Crafts and Conservation: Synthesis Report for ICCROM. [Online] Available at: http://www.iccrom.org/eng/02info_en/02_04pdf-pubs_en.shtml [Accessed 28 April 2010], p.7. 
to ritualized, and religious significance, and, or economic activity, which has a commercial outcome. It plays a role in defining regional, national or ethnic identity and culture. ${ }^{7}$

In India, craft has also been connected to the construction of nation hood and formation of identity in the country during post-independence. This is articulated by Ashoke Chatterjee, who writes, 'For almost 60 years, the Indian Government has been unique in its commitment to the craft sector, a legacy of the swadeshi movement and the ethos of a national identity fostered during the freedom movement. Unlike most developing countries in India, crafts have been given a place in national planning.' 8 Paradoxically, within India, there remain deep rooted perceptions that craft technologies and processes are backward, and even primitive, by present standards. Laila Tyabji says that for the craft person, craft is a profession that neither gives adequate economic returns or social status. She writes:

'While craft traditions are a unique mechanism for rural artisans entering the economic mainstream for the first time, they also carry the stigma of inferiority and backwardness, as India enters a period of hi-tech industrialization and globalization. Craft and the ancillary aspects of design and tradition are considered by activists and economists, bureaucrats and business strategists as decorative, peripheral and elitist - rather retrograde ways of earning a living. Craftspeople are always seen as picturesque exhibits of our past, rather than dynamic entrepreneurs of our present and future. ${ }^{9}$

Despite the efforts of government, and the implementation of policy designed to strengthen the sector, artisans themselves continue to be marginalized, their average earnings often well below the stipulated minimum wages. ${ }^{10}$

Furthermore, the push towards modernization and mechanization of the sector has crippled some sectors of the craft industry. For instance, it has been well documented that across the hand loom sector, the increase in power loom products has had a negative impact on the livelihoods of weavers. Mayank Kaul Singh notes that, whilst mechanization is an inevitable part of the evolution of crafts, the implications of introducing technology, in the current context and in the future, should not be ignored. Singh argues; 'We have seen that in most parts of the country, power looms have entered the manufacturing scene by their ability to provide handloom replicas at much cheaper cost. The mushrooming of power looms across the country has rapidly begun to shrink

7 Lucy Donkin, 2001. Crafts and Conservation: Synthesis Report for ICCROM. [Online] Available at: http://www.iccrom.org/eng/02info_en/02_04pdf-pubs_en.shtml [Accessed 28 April 2010], p.12. 8 Ashoke Chatterjee, 2006. The Indian Craft, Sunrise or Sunset in the Global Market, Craft Revival Trust [online] Available at: <http://www.craftrevival.org/voiceDetails.asp?Code=106 > [Accessed 18 April 2010].

9 Laila Tyabji, 2007. The Problem, Seminar Magazine [online] Available at: <http://www.indiaseminar.com/2007/570/570_problem.htm> [Accessed 28 April 2010].

10 lbid., 
the production, consumer and aesthetic base of handlooms. ${ }^{11}$ There are many instances, where imitation by machine processes, has adversely impacted small crafts communities, for instance, the impact upon weavers in Varanasi, with the production of imitation, Benares brocade, or, the screen printing of Ikat, has been observed. ${ }^{12}$ As Jaya Jaitly has observed; 'In the area of handmade goods, both crafts and textiles, even as countries like India are learning to convert their weaknesses into strengths, in China mechanization is efficiently organising itself to imitate the hand work of India to encroach upon the market for India's special skills.' ${ }^{13}$

In contrast to industrial production, the handmade qualities of craft, suggest a deeper engagement between, the maker and his or her product, a relationship in which the artisan has a personal history, and is materially aware of the processes, and techniques of production. Jaitly argues that this aspect of craft should be emphasised in marketing discourse. She says:

'Handicraft and handloom bazaars should not be popular just because we get 'arty' things at a fairly inexpensive rate but because health, environment, education, self value, exposition of cultural diversity and other such vitally important areas are linked to the need for sustaining crafts. ${ }^{14}$

Jaitly uses the example of how, if the government adopted a policy where the kulladh - the earthen cup made by potters all over India, was to be used in all government institutions, and services, has both employment and environmental benefits. She writes: 'The mud of the kulladh goes back into the earth without harming it. Hygiene is maintained by ensuring that it cannot be reused. Paper is saved and non-degradable plastic is avoided. ${ }^{15}$ Proponents of the Indian craft industry, such as Jatin Bhatt argue: 'Handicraft is a production process and a wonderful, indigenous technology, not an outmoded tradition. The raw materials (cane, cotton, clay, wood, wool, silk, minerals) are not only indigenously available but also environmentally friendly.' ${ }^{\prime 16}$

However, it would be wrong to assume that craft practices are, 'innately' ecologically responsible; in many cases, there has been an active intervention in which, sustainable practices and processes of production are introduced. For instance, AVANI, a craft and development NGO, located in the Kumaon Hills of

11 Mayank Kaul Singh, 2005. Evolution in Crafts: Negotiating the Handmade and the Machine Made, Craft Revival Trust [online] Available at: <http://www.craftrevival.org/voiceDetails. asp?Code=115> [Accessed 30 April 2010].

12 Mayank Kaul Singh, 2005. Evolution in Crafts: Negotiating the Handmade and the Machine Made, Craft Revival Trust [online] Available at: <http://www.craftrevival.org/voiceDetails. asp?Code $=115>$ [Accessed 30].

13 Jaya Jaitly, 2005. Crafts as Industry, Craft Revival Trust [online] Available at: <http://www.indiaseminar.com/2005/553/553\%20jaya\%20jaitly.htm> [Accessed 29 April 2010].

14 Jaya Jaitly. Make Crafts for Everyday Life for Growth, Craft Revival Trust [online] Available at: <http://www.craftrevival.org/voiceDetails.asp?Code=18> [Accessed 20 April 2010].

15 Jaya Jaitly, 1993. The Indian World Arts and Crafts Journal, Craft Revival Trust [online] Available at: <http://www.craftrevival.org/voiceDetails.asp?Code=18> [Accessed 22 April 2010].

16 Jatin Bhatt, 2007. Philosophy and Practice of Crafts and Design, Seminar Magazine,[online] Available at: <http://www.india seminar.com/2007/570/570_jatin_bhatt.html>[Accessed 30 April 2010]. 
the Himalayas, has been actively involved in 'greening' their production. AVANI has implemented sustainable processes, and has made a conscious effort to work on greening their production processes. They have applied new green technologies, and combined them with traditional techniques. All of AVANI' products, made from wild silks, pashmina and Tibetan sheep wool are spun on drop spindles and traditional spinning wheels called Bageshwari Charkhas. In order to help alleviate the physical hardship of their craft tradition, AVANI have developed prototypes of solar powered spinning wheels. ${ }^{17}$ Therefore, the need to improve working conditions for artisans, and at the same time, make them more efficient, has not compromised the low environmental impact of AVANI's traditional craft practices, which, did not consume electricity, or other resources.

AVANI has also instituted bioregionalism, which, is a key response to environmental degradation and resource depletion; that seeks to minimise resource consumption, through the encouragement of practices that draw upon local materials and energy sources. ${ }^{18}$ AVANI has encouraged the cultivation of eri and mulga silk by the farmers of the area, ensuring that the raw material base required for craft production is locally available. People also grow, and collect wild plants like turmeric, myrobolan, and pomegranate rind and walnut hulls, to use as natural dyes. These are also sold for natural paints, textile dyes, food colourants, and organic soaps. ${ }^{19}$ There have been many flow-on benefits from this initiative, for instance, the plantation of host trees required to produce eri and mulga silk, has led to the conservation of local fodder species, and the reforestation of wastelands, as the trees are native species. ${ }^{20}$

Furthermore, AVANI's practice of bioregionalism has provided livelihood support to over one hundred farmers who have adopted sericulture, as a source of supplementary income for their families. All the farmers have also been taught simple techniques, like mulching and vermin-composting for better survival and growth of the plants. Such investment in local resources reduces costs, eliminating the need to transport goods and materials over long distances, which, also minimizes energy use. AVANI also conserves fuel, through using green energy alternatives, such as solar power, and rainwater harvesting. For instance, rainwater, used for natural dyeing is pre heated in solar water heaters. The wastewater is then recycled and utilized for irrigation to grow vegetables. A wastewater recycling plant is presently under construction, this will recycle 80 $\%$ of all the water used at the centre.

Many Indian craft enterprises are also adapting traditional skills to create eco products, by reclaiming waste, recycling it and extending the life of a material, and, or object, by 'up- cycling', discarded material to create new products. Often, these recycled crafts, have emerged as a result of the creative use of

17 AVANI, 2010. Available at: <http://www.avani-kumaon.org> [Accessed 2 April 2010].

18 Alan Drengson \& Yuichi Inoue, The Deep Ecology Movement: An Introductory Anthology, North Atlantic Books, 1995.

19 AVANI, 2010. Available at: <http://www.avani-kumaon.org> [Accessed 2 April 2010].

20 AVANI, 2010. Available at: <http://www.avani-kumaon.org> [Accessed 2 April 2010]. 
waste in urban areas, and are the result of craft innovators, working with what is available. Jan Sandesh, a small NGO working from a slum in West Delhi, make beads from rags, as well as found, or donated newspaper and magazines, transforming them into personal accessories. They make hair clips fashioned into elephants, flowers, caterpillars, stars, and butterflies, from rags that are collected from local tailors. The women who make these objects have been able to respond to changing and irregular resource supplies, by imaginatively using different materials, and turning waste into a product with aesthetic value.

Similarly, Khamir Craft Resource Centre located in Bhuj, Gujurat, has begun a project making bags, and home ware items, such as cushion covers, from discarded plastic bags, re- interpreting traditional craft products and using a small frame loom for new products. The project was initiated by ART D'ECO, an enterprise that provides product and design development support to artisan groups in India. The project with Khamir employs local rag pickers who collect plastic bags from the nearby town of Bhuj, these are then sorted by colour, washed, and cut into strips. The weaver uses these strips as a warp and weft pattern on a loom, to make yardage. Khamir also make bathroom mats with plastic bags, which are cut and stitched narrowly, on a cement bag, with an inner tube from a car, on the inside, to give the mat grip, so that it does not slip away. Khamir are fusing new materials, with traditional skills, recycling discarded cement bags, which, are embroidered with brightly coloured wool, with typical Kachchh design.

This project provides new opportunities for weavers, whilst simultaneously generating employment to rag pickers, a community that is particularly vulnerable to the conditions of extreme poverty. Rag pickers continue to earn a very low income, and live in poor conditions, lacking access to water, sanitation and other basic infrastructure. As documented in, Livelihoods With Dignity, by the Alliance of Indian Waste Pickers, rag pickers face health and safety risks: exposure to dangerous waste, including toxic substances such as lead and asbestos, as well as faecal matter, broken glass, metal objects; exposure to diseases transmitted by vermin, flies and mosquitoes. Common complaints include back and limb pain, skin irritation, rashes, and high risk of tuberculosis, bronchitis, asthma, pneumonia, dysentery, and parasites. ${ }^{21}$ Similarly, there is a range of occupational health and safety concerns related to traditional craft processes. As identified in a report from the Hazards Centre New Delhi, commissioned by the All India Artisans and Craftworker's Welfare Association (AIACA), Baseline Study on Environment, Occupational Health and Safety Issues in the Crafts Sector, there are a range of complaints regarding body aches, sores, cuts, burns and calluses, lung and eye problems, deafness, fatigue and sleeplessness. ${ }^{22}$ The report looked at environmental and occupational health impacts in six different cottage industries: Hand Block Printing in Jaipur; Blue

21 Kagad Kach Patra Kashtakari Panchayat (KKPKP) \& Alliance of Indian Wastepickers (AIW), 2010. Livelihoods With Dignity [online] Available at: http://www.wiego.org [Accessed 2 April 2010]. 22 TraidCraft, AIACA and Co-optex, May 2010. Sustainable Textiles for Sustainable Development, Environmental, Occupational Health and Safety in the Craft Sector in India Baseline study of 
Pottery in Jaipur; Leather in Ajmer and Jaipur; Bell Metal in Orissa; Dhokra in Orissa and Ikkat in Pochampally. The findings of the report indicate that access to affordable technology can reduce drudgery, and improve the overall health indicators for artisans. In some instances, there is a requirement for mechanization; however, with technical interventions, the complex terrain of culture, tradition, and maintenance of skills needs to be negotiated. ${ }^{23}$

Despite efforts of fair trade businesses and others, both within India, and abroad to promote crafts that use sustainable practices and methods, many artisans have not been able to reach the export market. Often artisans, and, or craft enterprises lack marketing expertise, and distribution methods. All India Artisans' and Craft worker's Welfare Association's, (AIACA), market access program, Craftmark- Handmade in India, provides a platform for artisan products to be marketed. The Craftmark is a certification seal that verifies genuine, handmade products. The Craftmark helps to denote genuine Indian handicrafts, develop sector-wide minimum standards and norms for labelling a product as a handicraft, and increase consumer awareness of distinct handicraft traditions. Under this initiative, AIACA licenses the Craftmark logo for use by Craft-based businesses, cooperatives and NGOs for use on product tickets and labels. AIACA undertakes a program of marketing activities through participation in international trade fairs, such as Ambiente, Frankfurt, and the circulation of a commercial product catalogue, to link artisans with the market.

On the domestic front, opportunities for Indian artisans to sell their products are improving. Artisans can sell to mainstream consumer directly at annual markets, such as Dastkar's Nature Bazaar, which takes place in India's main cities, or at permanent markets such as Dilli Haat in New Delhi. There are established large retailers, such as, Fablndia, who promote, and sell handcrafted items, and new players, such as Mother Earth. This latest addition to the retail scene has been founded by Industree Crafts Foundation and has opened a flag ship store selling, 'green' home ware, and personal accessories, including apparel, over 11,000 square feet and across three floors in Bangalore. This departmentlike store was funded through investment by Future Group, India's largest retail chain, heralding the mainstreaming of craft goods.

However, this increase in demand has created a troubling paradox, with many artisans beginning to grapple with balancing new economic opportunities, and environmental sustainability issues. For instance, in regions of India, such as Kachchh, an arid area, where drought is not uncommon, the intense use of water required in block printing, has already impacted local production, as ground water resources continue to deplete. It is estimated that Kachch's block printing sector draws up to 25 lakh litres of water a day during peak season. ${ }^{24}$ Many

selected Craft Clusters [Online] Available at: <http://www.aiacaonline.org/pdf/research-baselinestudy-environment-occupational-health- safety-issues-the-crafts-sector.pdf> [Accessed 25 April 2010].

23 Ibid.

24 Khamir Craft Resource Centre, 2010. Available at:http://www.khamir.org [Accessed 5 May 2010]. 
artisans do not have access to sources of water, and the majority of printers must rent wadis or farms with water access, and bear the resulting expenses, transportation challenges, and pollution. ${ }^{25}$ The water scarcity issue has been further exacerbated, by the transition from natural dyes to chemical dyes, which has meant an increase in pollutants that are absorbed into the water table. Currently, Khamir is working on technologies to reduce contamination of the local environment, as well as water and energy consumption.

The negative environmental impacts from production processes, will impact the long term sustainability, and competitiveness of Indian textiles and craft in the long term. Currently, there are a number of projects, designed to minimize the risks associated with environmental collapse. AIACA, in partnership with the Traidcraft UK and COTEX, Rajasthan, with support from the European Union, is in the first stages of the four year SWITCH Asia Project (Promoting Sustainable Consumption and Production). The project will support the production of sustainable textiles in India, pioneering low cost technologies that can be used for water conservation, treatment and re-use. ${ }^{26}$ Under the sustainable production element, the project will assist the creation of an eco friendly textile park in Bagru, Rajasthan. This park will use environmentally friendly technologies for production; part of the project, includes building the necessary infrastructure, for water harvesting and conservation. This park will be used as a model, for best-practice environmental processes, which, it is hoped, will be adopted in 29 other textile parks across the country.

For some crafts, it would seem that volume production cannot provide a sustainable environmental, and livelihood option, and therefore, mainstream markets are not a viable option. For instance, there is Ajrakh, a resist block printing craft, from the Thar Desert region, that has a taxing environmental and production process. The process is laborious, involving a total of sixteen stages and large quantities of water are used. Ajrakh begins with the preparation of the material, this involves soaking the fabric in a mixture of camel dung, seed oil, and water, and it is then dried in the sun, with oil that has been curdled with carbonate of soda. The cloth is then washed and re-soaked in a home-made mixture of dried lemons, molasses, castor oil and water. After the proper preparation of the material, the Ajrakh is printed, usually with several different blocks of geometric shapes, layered over the textile, giving the Ajrakh its characteristic patterning. The cloth is dyed in stages, in different natural dyes, depending on the colour that wishes to be achieved, which include crimson, indigo, and yellow, created by the use of myrobalan, madder, indigo, root of rhubarb, and pomegranate

25 Khamir Craft Resource Centre, 2010. Available at:<http://www.khamir.org> [Accessed 5 May 2010].

26 All India Artisans and Craftworker's Welfare Association, 2010. Available at: www.aiacaonline. org [Accessed 1 June 2010]. 
peel. ${ }^{27}$ Despite this high level of specialization, Ajrakh continues to be traded, like many Indian handicrafts, as a low value commodity item on the global trade network that can be bought and sold in volume.

The Khatri community has been engaged in the making of Ajrakh for an estimated three thousand years, and the technique has been traditionally passed down through the generations with only a handful of artisans, possessing the knowledge, skill and expertise required to make Ajrakh. In recognition of his skills, and expertise, an Ajrakh artisan from Ajrakhpur in Kachchh, Professor, Ismail Mohammad Khatri, was awarded an honorary doctorate in textiles from De Montfort University of Leicester. Yet, despite these accolades, Ajrakh does not command the kinds of prices, ascribed to a valuable, high end art. An intellectual separation, between craft and art continues to impact prices, with fine art continuing to be regarded as superior. A constricted market for high end crafts, places market-driven pressure on artisans, forcing them to create low cost handicrafts, which could mean the loss of particular skills, and traditions. The devaluing of crafts is further exacerbated by the limited opportunities for Indian artisans to exhibit their work in a fine art context. There are efforts to promote excellence in craft, set quality standards, and recognize the talents of craftspeople, via the UNESCO Award of Excellence, along with the Government of India's National Award for Master Craftsperson, yet, these have not gone far enough in supporting artisans to achieve status in the mainstream community.

Indian crafts would be assisted by a permanent space in India's cities, which could elevate the work of talented, and or, master craftspeople, to a transcendental and exclusive object. The Crafts Museum in New Delhi has the potential to operate as a space for showcasing the best of Indian design and craft. The National Gallery of Modern Art could function as a space to position Indian craft in a modern, contemporary context, and, at the same time, raise the value attached to craft, in general. Both need to employ curatorial practices and strategies that can facilitate a real engagement with craft, where craft can be explored, discussed and valorised. With the lack of a national public space in which, craft can be exhibited and displayed, with sensitivity to its history and materials, there exists little opportunity to change perceptions that associate with craft with a low aesthetic standard, and little chance of developing Indian craft into an elite genre. The state needs to support such an endeavour, to define and construct a place for craft that places it within a contemporary context. By providing a framework for generating value around craft, there is the potential to create a more sustainable livelihood base for artisans and craft workers, particularly given the growing environmental pressures, and issues related to the depletion of resources, that could make volume production untenable.

The concept of 'sustainability' in relation to Indian crafts is connected to environmental, cultural and economic concerns. Craft provides employment opportunities, and the ability to earn an income from craft contributes to the

27 See Emma Ronald, Ajrakh Patterns and Borders, Anokhi Museum of Hand Printing, AMHP Publications, Rajasthan, 2007. 
longevity of cultures, and craft communities. In the current context, a review of the ethics around consumption, and a desire for an alternative to industrial production, has opened up the market for Indian craft.

In particular, craft enterprises that utilize, and, or adopt environmentally responsible practices, are well positioned to tap into emerging markets. AIACA's market access

initiative, Craftmark-Handmade in India, provides market linkages and valuable marketing support for craft groups to tap into urban consumer markets. However, demand for crafts needs to be properly managed, as an increase for particular types of craft, such as block printing, carries environmental challenges. There must be an ongoing effort to support crafts that are ecologically responsible, and, to encourage artisans to institute environmental management practices, and natural resource management, to ensure their ongoing survival. Similarly, there must be an effort to elevate crafts to desirable, high end fine art products, and to recognize their cultural, social and economic contribution to modern India.

\section{Bibliography}

Baxter, M., 2003. Threads of Life, Seminar Magazine, [online] Available at: <http:// www.india- seminar.com/2003/523/523maggiebaxter.htm> [Accessed 25 April 2010].

Bhatt, J., 2007. Philosophy and Practice of Crafts and Design, Seminar Magazine, [online] Available at: <http://www.india-seminar.com/2007/570/570_jatin_ bhatt.html> [Accessed 30 April 2010].

Chatterjee, A., 2006. The Indian Craft, Sunrise or Sunset in the Global Market, Craft Revival Trust [online] Available at: <http://www.craftrevival.org/ voiceDetails.asp?Code=106 $>$ [Accessed 18 April 2010].

Donkin, L., 2001. Crafts and Conservation: Synthesis Report for ICCROM. [Online] Available at: <http://www.iccrom.org/eng/02info_en/02_04pdfpubs_en.shtml> [Accessed 28 April 2010].

Drengson, A., and Inoue, Y., 1995. The Deep Ecology Movement: An Introductory Anthology, North Atlantic Books.

Jaitly, J., 1993. The Indian World Arts and Crafts Journal, Craft Revival Trust [online] Available at: <http://www.craftrevival.org/voiceDetails. asp?Code=18> [Accessed 22 April 2010].

Jaitly, J., 2005. Crafts as Industry, Craft Revival Trust [online] Available at: <http:// www.india-seminar.com/2005/553/553\%20jaya\%20jaitly.htm> [Accessed 29 April 2010]. 
Jaitly, J., 2005. Make Crafts for Everyday Life for Growth, Craft Revival Trust [online] Available at: <http://www.craftrevival.org/voiceDetails. asp?Code $=18>$ [Accessed 20 April 2010].

Jaitly, J., 2007. Employment in the Craft Sector, One India, One People, [online] Available at: <http://www.craftrevival.org/voiceDetails.asp?Code=176> [Accessed 20 April 2010].

Wood, S., 2011, Sustaining crafts and livelihoods: handmade in India craft + design enquiry, vol. 3

Kaul Singh, M., 2005. Evolution in Crafts: Negotiating the Handmade and the Machine Made, Craft Revival Trust [online] Available at: <http://www. craftrevival.org/voiceDetails.asp?Code $=115>$ [Accessed 30 April 2010].

Nicholls, A. and Opal, C., 2005. Fair Trade: Market-Driven Ethical Consumption. Sage Publications Ltd.

Ronald, E., 2007. Ajrakh Patterns and Borders, Anokhi Museum of Hand Printing, AMHP Publications, Rajasthan.

Tyabji, L., 2007. The Problem, Seminar Magazine [online] Available at: <http:// www.india- seminar.com/2007/570/570_problem.htm> [Accessed 28 April 2010]. 